\title{
An Affinity-Based Method for the Purification of Fluorescently-Labeled Biomolecules
}

\author{
Trung Nguyen, Neel S. Joshi and Matthew B. Francis* \\ Department of Chemistry, University of California, Berkeley, CA 94720-1460, and \\ Materials Sciences Division, Lawrence Berkeley National Labs, Berkeley, CA 94720
}

\section{Supporting Information}

General Procedures. Unless otherwise noted, all chemicals were obtained from commercial sources and used without further purification. All small molecule reactions were carried out under a nitrogen atmosphere in oven dried glassware unless otherwise noted. All organic solvents were removed under reduced pressure using a rotary evaporator. Pyridine was distilled under an inert atmosphere from calcium hydride. Water $\left(\mathrm{ddH}_{2} \mathrm{O}\right)$ used in biological procedures or as a reaction solvent was deionized using a NANOpure $^{\mathrm{TM}}$ purification system (Barnstead, USA). Myoglobin (M 1882) from horse heart, Subtilisin Carlsberg protease (P5380) from Bacillus licheniformis, and $\alpha$ chymotrypsinogen A (P 5380) from bovine pancreas were purchased from Sigma (St. Louis, USA) and used without further purification. Size exclusion chromatography was performed using NAP $^{\mathrm{TM}} 5$ columns from Amersham Biosciences. Microspin $^{\mathrm{TM}} \mathrm{G}-25$ columns were purchased from Amersham Biosciences. The pre-packed Sephadex resin was discarded and the columns were thoroughly washed prior to use. Dyes used for protein labeling experiments were purchased from Invitrogen and used without further purification. Samples were mixed using a Barnstead Thermolyne Labquake® Shaker Rotisserie. NHS-activated Sepharose ${ }^{\mathrm{TM}} 4$ Fast Flow resin (17-0906-01) was purchased from Amersham Biosciences. 6-monodeoxy-6-monoamino- $\beta$-cyclodextrin (M 2314) and $\beta$-cyclodextrin hydrate (856088) were obtained from Aldrich Chemical Company. 
Instrumentation and Sample Analysis Preparations. UV-Vis spectroscopic measurements were conducted on a Tidas-II benchtop spectrophotometer (J \& M, Germany).

Matrix assisted laser desorption-ionization time-of-flight mass spectrometry (MALDI-TOF MS) was performed on a Voyager-DE ${ }^{\mathrm{TM}}$ system (PerSeptive Biosystems, USA). All samples were co-crystallized using either an $\alpha$-cyano-4-hydroxycinnamic acid or a sinapinic acid solution (10 mg/mL in $1: 1 \quad \mathrm{MeCN} \mathrm{ddH}_{2} \mathrm{O}$ with $0.1 \%$ TFA). Electrospray LC/MS analysis was performed using an API 150EX system (Applied Biosystems, USA) equipped with a Turbospray source and an Agilent 1100 series LC pump. Protein mass reconstruction was performed on the charge ladder with Analyst software (version 1.3.1, Applied Biosystems). Prior to MS analysis, biological samples were desalted and/or separated from small molecule contaminants using $\mu \mathrm{C} 18 \mathrm{ZipTip}^{\circledR}$ pipet tips (Millipore, USA), NAP-5 ${ }^{\mathrm{TM}}$ columns (Amersham Biosciences, USA), Strata C$18 \mathrm{E}^{\mathrm{TM}}$ reversed-phase columns (Phenomenex, USA), or 3500 molecular weight cutoff Slide-A-Lyzer® Dialysis Cassettes (Pierce Biotechnology, Inc., USA) as indicated below. Intact protein chromatography was performed using a Jupiter 5u C5 $300 \AA$ reversed phase column $(2.0 \mathrm{~mm} \times 150 \mathrm{~mm})$ with a $\mathrm{ddH}_{2} \mathrm{O}: \mathrm{MeCN}$ gradient mobile phase containing $0.1 \%$ formic acid $(250 \mu \mathrm{L} / \mathrm{min})$. An Agilent Zorbax $3.5 \mu \mathrm{m}$ 300SB-C8 reversed phase column $(2.1 \mathrm{~mm} \times 50 \mathrm{~mm})$ was used for the analysis of trypsin digest fragments.

For protein analysis, sodium dodecyl sulfate-polyacrylamide gel electrophoresis (SDS-PAGE) was accomplished on a Mini-Protean apparatus (Bio-Rad, USA), following the general protocol of Laemmli. ${ }^{1}$ Crude reaction mixtures were diluted by a factor of 5 
$(\mathrm{v} / \mathrm{v})$ in $\mathrm{ddH}_{2} \mathrm{O}$ and combined 1:1 (v/v) with gel loading buffer containing SDS, DTT, and bromophenol blue. Samples were then loaded onto the gel without heating. After removal of the completed gels from their cassettes, the bottom portions containing free dye were excised promptly, after which the gels were submerged in water for rinsing and imaging. Commercially available markers (Bio-Rad, USA) were applied to at least one lane of each gel for calculation of apparent molecular weights. Fluorescence visualization of gels was obtained by UV transillumination at $302 \mathrm{~nm}$. Visualization of protein bands was accomplished by staining with Coomassie ${ }^{\circledR}$ Brilliant Blue R-250 (BioRad, USA). Gel imaging was performed on an EpiChem3 Darkroom system (UVP, USA).

General procedure for fluorescent labeling of proteins. In a typical procedure, $3.5 \mathrm{~mL}$ of a $0.1 \mathrm{mM}$ myoglobin solution in $0.1 \mathrm{M} \mathrm{NaHCO}_{3} \mathrm{pH} 8.3$ aqueous buffer was transferred to a centrifuge tube. An amine reactive fluorophore $(\sim 1 \mathrm{mg})$ in $20-40 \mu \mathrm{L}$ of DMF was then added. The solution was stirred on a laboratory mixer for $2.5 \mathrm{~h}$ and then quenched with $0.1 \mathrm{M} \mathrm{H}_{2} \mathrm{NOH} \mathrm{pH} 7.2(80 \mu \mathrm{L}, 8.0 \mu \mathrm{mol})$ aqueous solution. The reaction was then mixed overnight at room temperature. For specific examples of protein labeling reactions refer to Table 1. A portion of the crude reaction was purified by size exclusion chromatography. The purified solution was analyzed by UV-vis spectroscopy, MALDITOF-MS or ESI-MS, and SDS-PAGE. The sample used for many of the experiments presented in the supporting information will be referred to as $\mathbf{S 1}$ (see Table S1) 
Table S1. Fluorescent labeling of myoglobin with amine reactive dyes.

\begin{tabular}{lccl}
\hline Dye/fluorophore & $\begin{array}{c}\text { Conjugate } \\
\#\end{array}$ & $\begin{array}{c}\text { Eq. of dye } \\
\text { added }\end{array}$ & $\begin{array}{c}\text { Conjugates } \\
\text { detected }^{\mathbf{1}}\end{array}$ \\
\hline Oregon Green 488 carboxylic acid SE & $\mathbf{4}$ & 1.0 & Unmod, $+1,+2$ \\
TAMRA-NHS & $\mathbf{6}$ & 5.0 & $+2,+3,+4,+5$ \\
Cascade Blue acetyl azide & $\mathbf{7}$ & 5.0 & Unmod, $+1,+2$ \\
Alexa Fluor 350 carboxylic acid SE & $\mathbf{8}$ & 5.0 & $+2,+3,+4,+5$ \\
Oregon Green 488-X-succinimidyl ester & $\mathbf{S 1}$ & 5.0 & Unmod, $+1,+2,+3$ \\
\hline
\end{tabular}

Extent of labeling was determined by MALDI-TOF or ESI-LC MS. Only predominant species present in the spectra were reported.

Quantification of sepharose resin coupling reaction. In order to quantify the degree of modification to the NHS-activated sepharose resin the Amersham literature procedure was employed. To analyze the amount of NHS hydrolyzed during a coupling experiment, a calibration curve was formed by monitoring the absorbance at $260 \mathrm{~nm}$ for serial dilutions of a $30 \mathrm{mM} \mathrm{NHS}$ aqueous solution in $0.2 \mathrm{M} \mathrm{NaHCO}_{3} / 0.5 \mathrm{M} \mathrm{NaCl} \mathrm{pH} 8$ buffer. For coupling reactions to the NHS-activated resin, Amersham Biosciences literature values predicted concentrations of released NHS to be from $16-23 \mu \mathrm{mol} / \mathrm{mL}$ of resin.

Synthesis of $\beta$-cyclodextrin modified sepharose resin (2a). NHS-activated resin was transferred to a fritted column as a slurry and filtered to dryness. The resin occupied a volume of $17.5 \mathrm{~mL}$. A solution of 6-monodeoxy-6-monoamino-cyclodextrin $(0.44 \mathrm{~g})$ in $10 \mathrm{~mL} 0.2 \mathrm{M} \mathrm{NaHCO}_{3} / 0.5 \mathrm{M} \mathrm{NaCl} \mathrm{pH} 8$ aqueous buffer was added to the resin. The column was then capped and agitated on a laboratory shaker for $2 \mathrm{~h}$. The reaction tube was drained and the eluting solvent was collected for subsequent analysis. Afterwards, the resin was subjected to the following series of washes:

- 3 washes of $0.2 \mathrm{M} \mathrm{NaHCO}_{3} / 0.5 \mathrm{M} \mathrm{NaCl} \mathrm{pH} 8$ aqueous buffer ( $10 \mathrm{~mL}$ portions)

- 3 washes of $0.5 \mathrm{M}$ ethanolamine $/ 0.5 \mathrm{M} \mathrm{NaCl} \mathrm{pH} 8.3$ aqueous buffer $(10 \mathrm{~mL}$ portions) 
- 3 washes of $0.1 \mathrm{M}$ acetate/ $0.5 \mathrm{M} \mathrm{NaCl} \mathrm{pH} 4$ aqueous buffer (10 mL portions)

- 1 wash of $\mathrm{H}_{2} \mathrm{O}(10 \mathrm{~mL}$ portions $)$

- 2 washes of $25 \mathrm{mM}$ phosphate buffer $\mathrm{pH} 7$ (10 $\mathrm{mL}$ portions)

- 3 washes of $\mathrm{H}_{2} \mathrm{O}(200 \mathrm{~mL}$ portions)

The resin was then stored as a slurry in $\mathrm{H}_{2} \mathrm{O}$ at $4{ }^{\circ} \mathrm{C}$.

The eluting fraction from the coupling reaction was determined to contain 153 $\mu \mathrm{mol}$ of NHS. This corresponds to a cyclodextrin loading of $8.7 \mu \mathrm{mol} / \mathrm{mL}$ of dry resin. Expected values for NHS release during this reaction were $280-403 \mu \mathrm{mol}$ according to Amersham loading values.

Synthesis of amino $\beta$-cyclodextrin derivative (1b). $\beta$-cyclodextrin monohydrate was placed in a flask as a solid and dried under vacuum at $50{ }^{\circ} \mathrm{C}$ overnight. The dry cyclodextrin $(1.0 \mathrm{~g}, 0.86 \mathrm{mmol})$ was transferred to a new flask and dissolved in freshly distilled pyridine $(3.0 \mathrm{~mL})$. A solution of carbonyldiimidazole $(140 \mathrm{mg}, 0.86 \mathrm{mmol})$ dissolved in $1 \mathrm{~mL}$ of freshly distilled pyridine was added to the reaction mixture dropwise over 2 minutes while stirring. The activation reaction was allowed to proceed at $\mathrm{rt}$ for $2 \mathrm{~h}$. After this time, the activated cyclodextrin solution was added dropwise to a flask containing 1,3-diaminopropane $(360 \mu \mathrm{L}, 4.32 \mathrm{mmol})$ while stirring. After $1 \mathrm{~h}$, the cyclodextrin mixture was precipitated by adding the reaction solution dropwise to a flask containing $500 \mathrm{~mL}$ of $\mathrm{CH}_{2} \mathrm{Cl}_{2}$ with vigorous stirring. The flaky white precipitate was isolated via suction filtration through filter paper, then placed under vacuum overnight. The cyclodextrin mixture was analyzed by MALDI-TOF mass spectrometry (Figure S1) and used without further purification. 


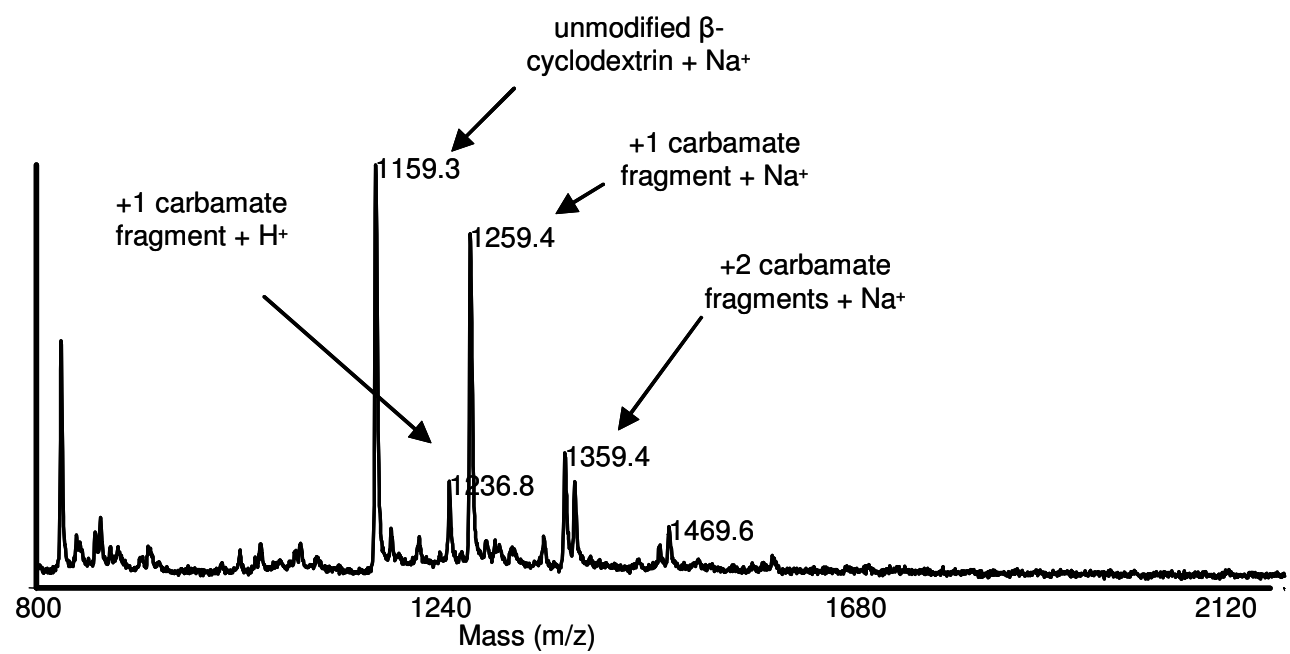

Figure S1. MALDI-TOF spectrum of $\mathbf{1 b}$ using $\alpha$-cyano-4-hydroxycinnamic acid matrix. Expected mass for $\beta$-cyclodextrin $[\mathrm{M}+\mathrm{Na}]+=1158.0$. Other peaks correspond to additions of the $100 \mathrm{Da}$ carbamate fragment (see Figure 1 in main text).

Synthesis of $\boldsymbol{\beta}$-cyclodextrin modified Sepharose resin (2b). Sepharose-NHS resin slurry $(0.5 \mathrm{~mL})$ was placed in a fritted tube and filtered. To the dry resin was added a solution of $\mathbf{1 b}\left(75 \mathrm{mg}\right.$ in $1.5 \mathrm{~mL}$ of $\left.\mathrm{NaHCO}_{3}(0.1 \mathrm{M}), \mathrm{NaCl}(0.5 \mathrm{M}), \mathrm{pH}\right)$ ). The resulting slurry was agitated overnight. The resin was then subjected to the following rinses:

- $3 x 1 \mathrm{~mL}$ of $0.5 \mathrm{M}$ ethanolamine/ $0.5 \mathrm{M} \mathrm{NaCl} \mathrm{pH} 8$

- $3 \times 1 \mathrm{~mL} 0.1 \mathrm{M}$ acetic acid/0.5 M NaCl pH 4

- $2 \times 20 \mathrm{~mL} \mathrm{H}_{2} \mathrm{O}$

The resin was stored at $4{ }^{\circ} \mathrm{C}$ as a slurry in water.

General procedure for resin capture of proteins. First, the crude protein solution was purified by size-exclusion chromatography using a NAP ${ }^{\mathrm{TM}} 5$ column into pure $\mathrm{H}_{2} \mathrm{O}$ or into the appropriate buffer solution. To a microcentrifuge tube containing 10-20 mg of dry CD modified sepharose resin, the purified protein (100-200 $\mu \mathrm{L}$ of $60 \mu \mathrm{M}$ solution) was added. Additional water was added to the heterogeneous solution to ensure proper mixing of the resin and protein solution. The solution was then agitated on a laboratory mixer for approximately 5 min. The heterogeneous solution was then transferred to a fritted microspin column and spun dry. 
The eluting solvent was collected in microcentrifuge tubes. It was observed that the color of the protein solution had been transferred to the resin. Water $(0.5 \mathrm{~mL})$ was then added to the column and mixed by manual inversion for $1 \mathrm{~min}$. The resin was rinsed with additional amounts of $\mathrm{H}_{2} \mathrm{O}$. To elute the protein, $0.5 \mathrm{~mL}$ of $10 \mathrm{mM}$ adamantane carboxylic acid/100 $\mathrm{mM} \mathrm{NH}_{4} \mathrm{Cl} \mathrm{pH} 7$ was added to the resin and inverted by hand for 1 min. The color of the eluting solution resembled that of the beginning protein solution. Additional washes with the eluting solvent mixture were performed to achieve higher levels of protein recovery. The eluting fractions were analyzed by UV-vis spectroscopy (Figure S2), and SDS-PAGE (Figure S3).

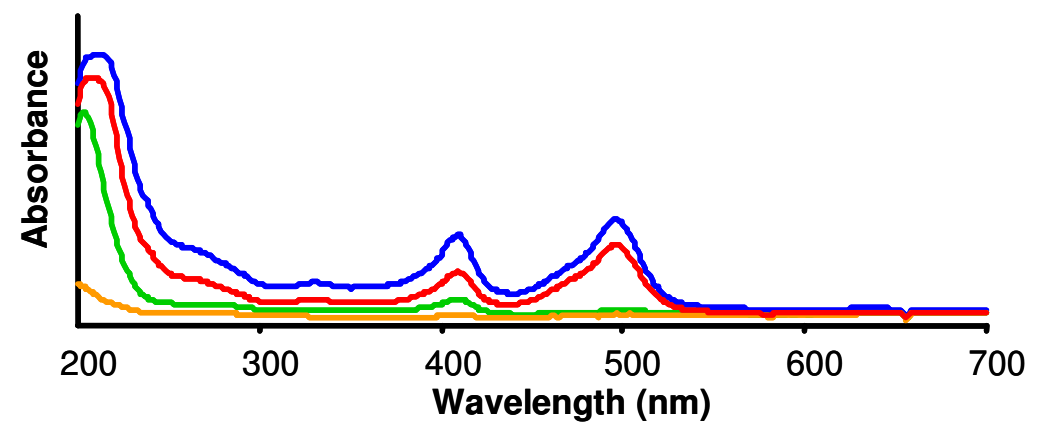

Figure S2. UV-vis spectrum of resin $\mathbf{2 b}$ capture of S1: before exposure to resin (blue), flow through after resin exposure (green), $\mathrm{H}_{2} \mathrm{O}$ washes of resin (orange), elution off of resin with $10 \mathrm{mM}$ adamantane carboxylic acid, $100 \mathrm{mM} \mathrm{NH}_{4} \mathrm{Cl}$, pH 7 (red). 
a)

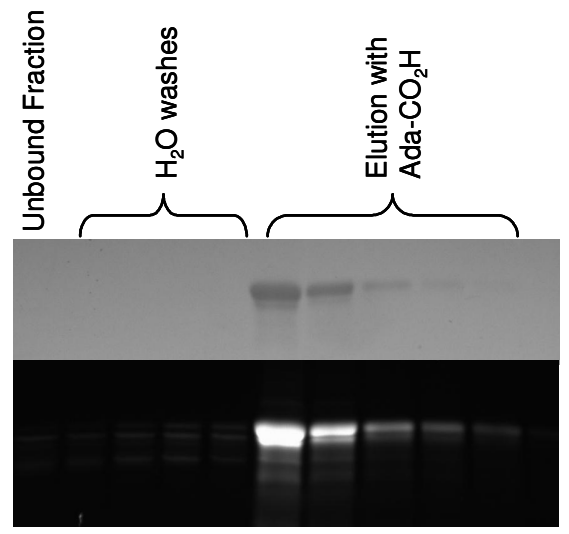

c)

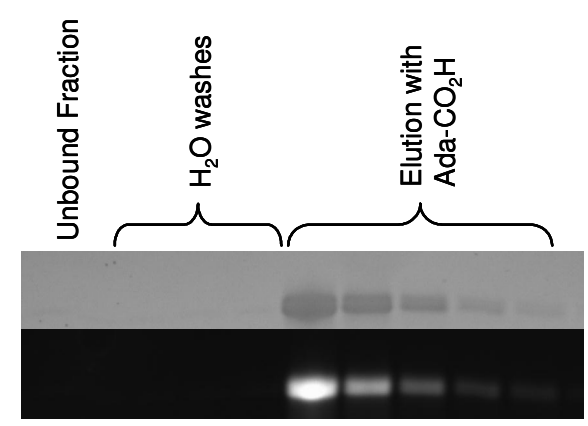

b)

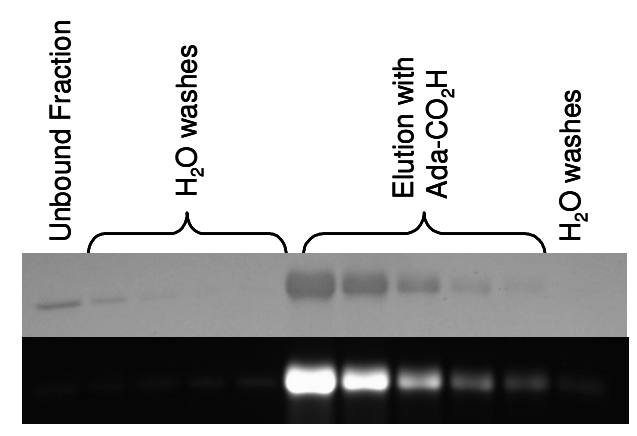

d)

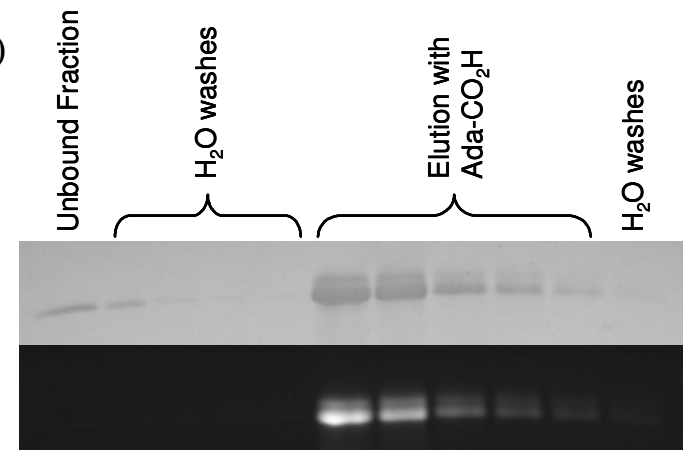

Figure S3. SDS PAGE analysis of eluting fractions for a) TAMRA labeled myoglobin b) Oregon Green labeled myoglobin c) Alexa Fluor 350 labeled myoglobin d) Cascade Blue labeled myoglobin.

SDS-PAGE quantification of modified protein recovery. SDS-PAGE analysis was used to quantify the amount of modified protein recovered by the resin. The values in the “\% fluorescence" column of Table 1 were calculated in the following manner:

Using the fluorescent images of the gels in Figure S3 as an example,

$\%$ fluorescence $=100 *($ sum of fluorescence in elution lanes $) /($ sum of fluorescence in all lanes $)$

The fluorescence in each lane was quantified using ImageJ $1.34 \mathrm{~s}$, an image processing and analysis program available free from the NIH website (http://rsb.info.nih.gov/ij/download.html). 
a)
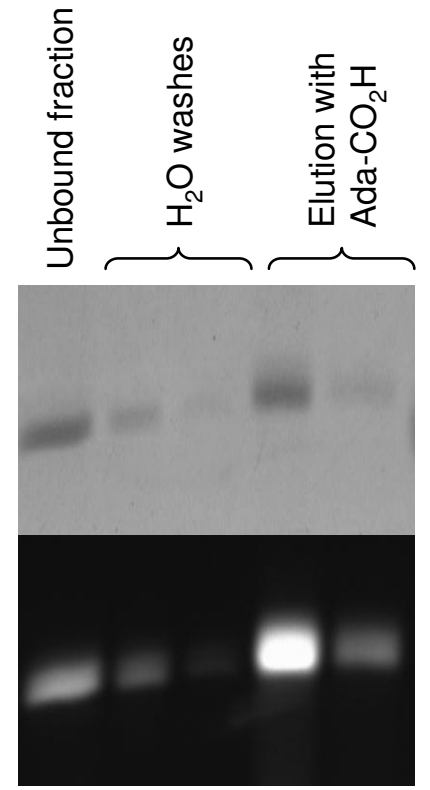

b)

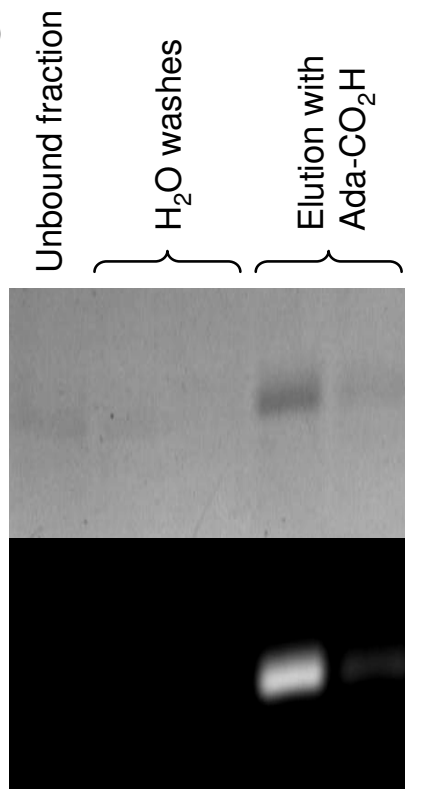

Figure S4. SDS-PAGE analysis of eluting fractions for Oregon Green-labeled myoglobin in the presence of a) $100 \mathrm{mM}$ sodium phosphate buffer and b) $100 \mathrm{mM}$ HEPES buffer. These samples correspond to entries 2 and 5 in Table S1.

Protein binding in commonly used buffer solutions. A solution of $\mathbf{S 1}$ was diluted into 4 different buffers (Tris, HEPES, $\mathrm{NH}_{4} \mathrm{OAc}$, and phosphate) to a final buffer concentration of $0.1 \mathrm{M}, \mathrm{pH} 7$. These solutions were then added to centrifuge tubes containing resin $\mathbf{2 a}$. The proteins were purified as described in the protein purification procedure. The eluting fractions were analyzed by SDS-PAGE and UV-vis spectroscopy (Figures S4 and S5). 

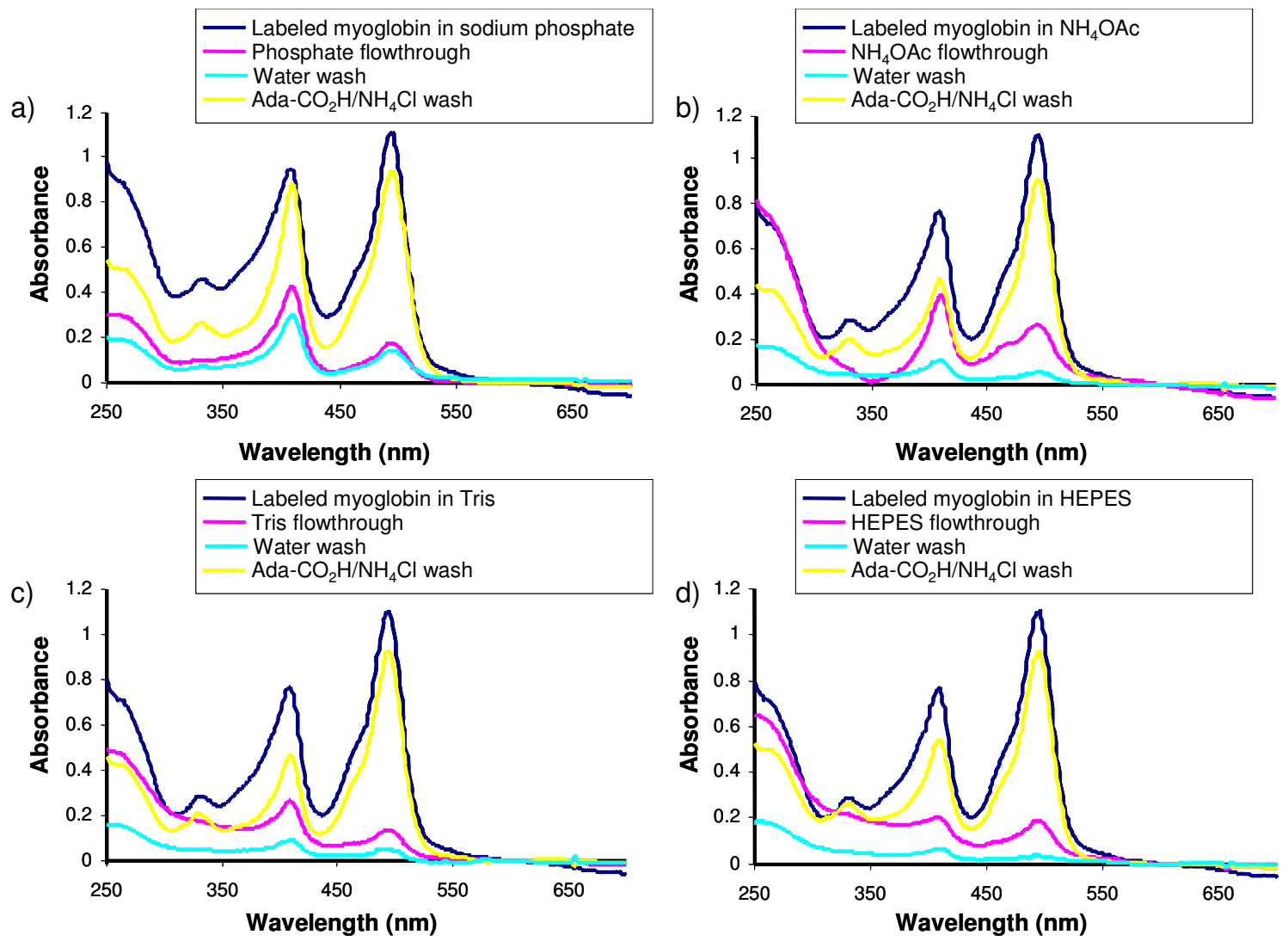

Figure S5. UV-vis spectra of Oregon Green-labeled myoglobin binding to resin 2a in commonly used buffers (each $0.1 \mathrm{M}, \mathrm{pH}$ 7) a) sodium phosphate b) $\mathrm{NH}_{4} \mathrm{OAc}$ c) Tris d) HEPES.

Adamantane effects on protein binding. Resin $2 \mathbf{a}(71.4 \mathrm{mg})$ was suspended in $500 \mu \mathrm{L}$ of $10 \mathrm{mM}$ adamantane carboxylic acid/100 $\mathrm{mM} \mathrm{NH}_{4} \mathrm{Cl} \mathrm{pH} 7$ and then agitated for $15 \mathrm{~min}$ by a laboratory mixer. The solution was transferred to separate microspin columns and spun dry. A solution of $\mathbf{S 1}(250 \mu \mathrm{L})$ was diluted to $1 \mathrm{~mL}$ and added to the respective resin in a centrifuge tube. The heterogeneous solution was mixed for 5 min. Afterwards, the solution was transferred to microspin column and spun dry. The eluent was analyzed by UV-vis spectroscopy. The resin was then washed with $500 \mu \mathrm{L} \mathrm{H}_{2} \mathrm{O}(2 \mathrm{x})$. The collected washes were analyzed by UV-vis spectroscopy. A final wash was performed with $500 \mu \mathrm{L} 10 \mathrm{mM}$ adamantane carboxylic acid/100 mM NH $\mathrm{NH}_{4} \mathrm{Cl}$ ). The collected washes were also analyzed by UV-vis spectroscopy (Figure S6). 


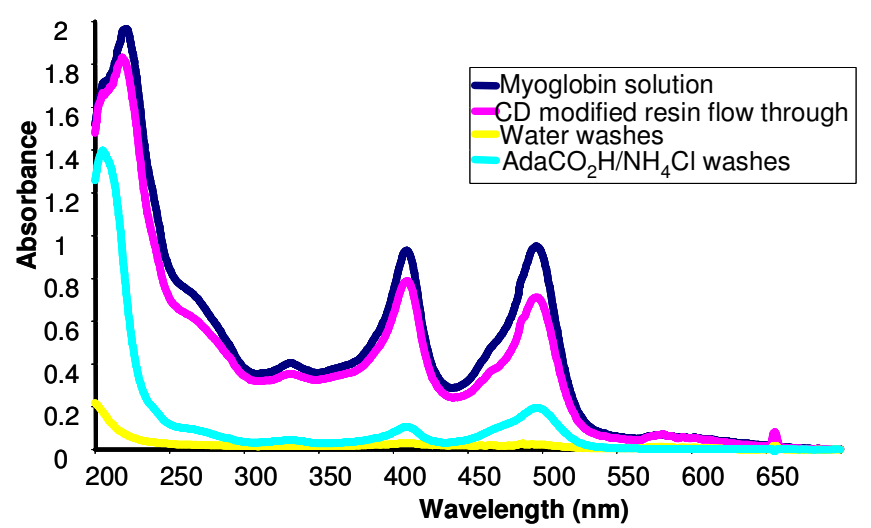

Figure S6. UV-vis spectra of $\mathbf{S 1}$ exposed to resin 2a pre-washed with $10 \mathrm{mM}$ adamantane carboxylic acid/100 $\mathrm{mM} \mathrm{NH}_{4} \mathrm{Cl} \mathrm{pH} 7$ solution.

MALDI-TOF MS analysis of the resin. To resin 2a (33.2 mg), $50 \mu \mathrm{L}$ of myoglobin conjugate 4 and $250 \mu \mathrm{L}$ of $\mathrm{H}_{2} \mathrm{O}$ were added. After mixing for $5 \mathrm{~min}$, the heterogeneous solution was spun dry in a microspin column. The resin was then washed with $500 \mu \mathrm{L}$ of $\mathrm{H}_{2} \mathrm{O}$ and a small portion of the dry resin was cocrystallized with sinapinic acid on a MALDI plate for analysis. The remaining resin was washed with $500 \mu \mathrm{L}$ of $10 \mathrm{mM}$ adamante carboxylic acid/100 $\mathrm{mM} \mathrm{NH}_{4} \mathrm{Cl} \mathrm{pH} 7$ buffer. The aqueous fractions were then analyzed by MALDI-TOF MS (Figure S7). 


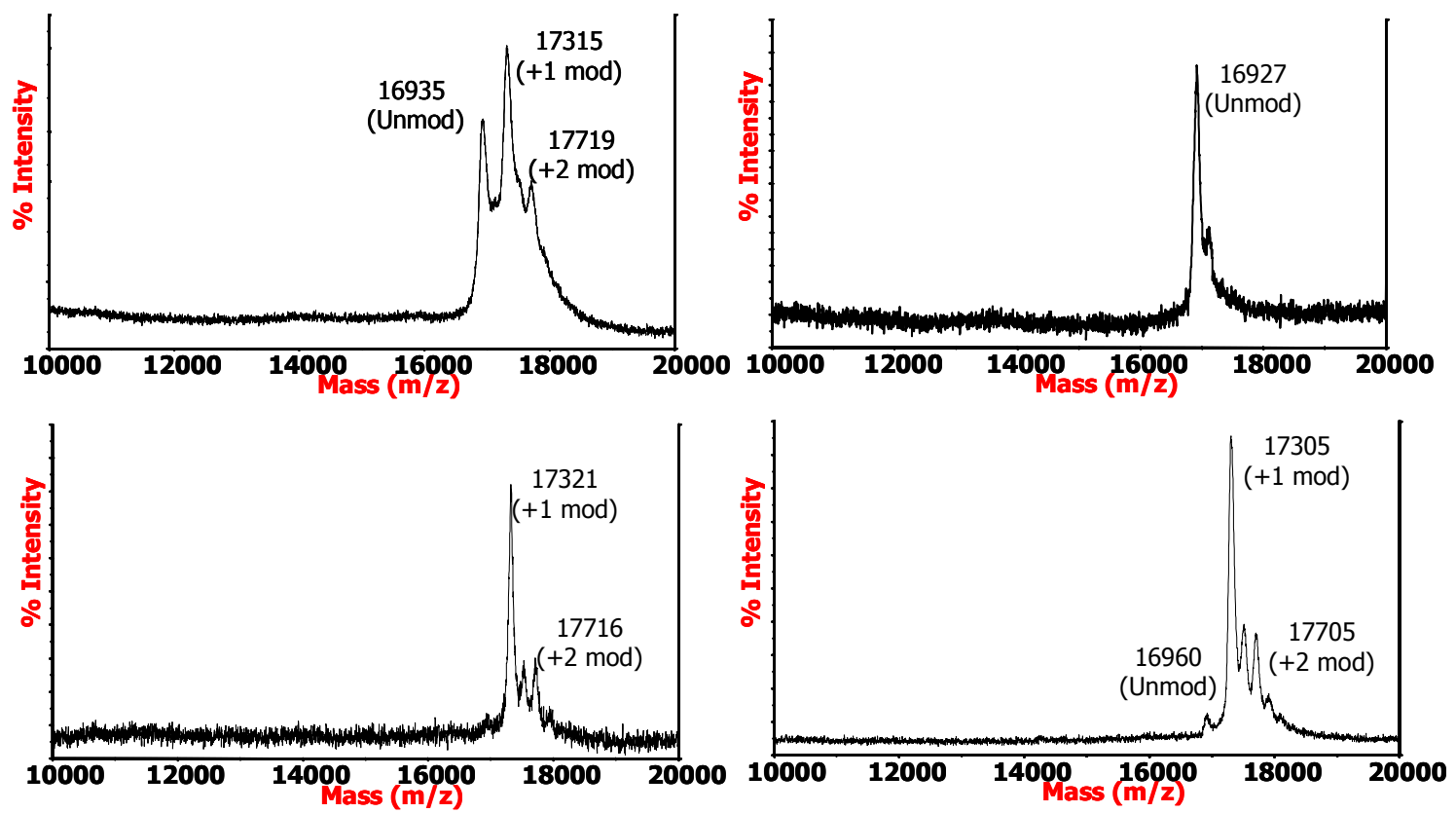

Figure S7. MALDI-TOF spectrum of a) Oregon Green labeled myoglobin b) aqueous flow through solution c) cyclodextrin modified sepharose resin after exposing to a solution of Oregon Green labeled myoglobin d) the eluting solution from the $10 \mathrm{mM}$ adamantane carboxylic acid/100 $\mathrm{mM} \mathrm{NH}_{4} \mathrm{Cl} \mathrm{pH} 7 \mathrm{wash}$

Procedure for enrichment of modified trypsin digest fragments. $50 \mathrm{~mL}$ of a solution of myoglobin conjugate $6(1 \mathrm{mg} / \mathrm{mL})$ was combined with $50 \mu \mathrm{L}$ of acetonitrile. DTT was added to the resulting solution to a final concentration of $10 \mathrm{mM}$. The protein was denatured at $65^{\circ} \mathrm{C}$ for $1 \mathrm{~h}$. The denatured protein solution was diluted by the addition of $0.45 \mathrm{~mL}$ of $50 \mathrm{mM} \mathrm{NH} \mathrm{HCO}_{3}, \mathrm{pH}$ 7.8. Trypsin (Promega Sequencing Grade) was then added to the myoglobin solution in a 1:100 (w/w) ratio. After 5 hours of incubation at 37 ${ }^{\circ} \mathrm{C}$, the proteolysis solution was lyophilized overnight. The peptide mixture was dissolved in $200 \mu \mathrm{L}$ of water and divided into two $100 \mu \mathrm{L}$ portions. To one portion was added $5 \mathrm{mg}$ of dry resin $\mathbf{2 a}$. The heterogeneous mixture was agitated for $5 \mathrm{~min}$ before being transferred to an empty MicroSpinTM (Amersham) column and centrifuged at $14,500 \mathrm{rpm}$ for $30 \mathrm{~s}$. The dry resin, which appeared brown due to the capture of modified peptides, was washed twice with $200 \mu \mathrm{L}$ aliquots of $\mathrm{H}_{2} \mathrm{O}$. The resin was then washed with one $100 \mu \mathrm{L}$ aliquot of $10 \mathrm{mM}$ adamantane carboxylic acid, $100 \mathrm{mM} \mathrm{NH}_{4} \mathrm{Cl}, \mathrm{pH} 7$. 
The brown color was transferred from the resin to the solution. Aliquots from before and after the resin capture procedure were both analyzed by LC-ESI MS (Figures S8).

a)

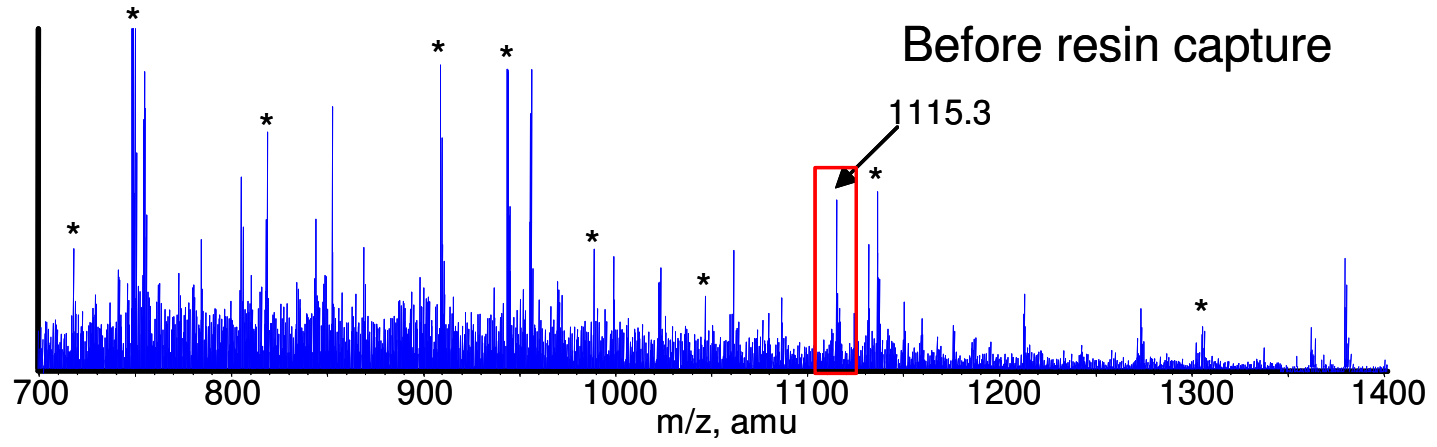

b)

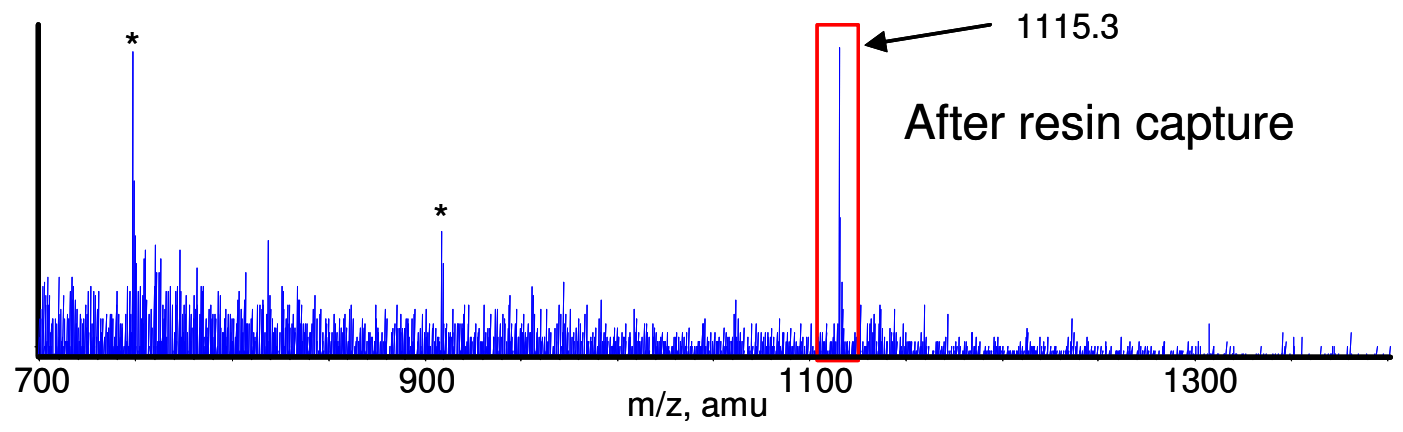

Figure S8. LC-MS analysis of modified trypsin fragments from digestion of TAMRA modified myoglobin: amass spectrum of trypsin fragments before resin capture. Starred masses represent unmodifed trypsin digest fragments. ${ }^{b}$ mass spectrum of trypsin fragments after elution from 2a with adamantane- $\mathrm{CO}_{2}{ }^{-}$ solution. Modified N-terminal fragment (GLSDGEWQQVLNVWGK) expected m/2 = 1115.5. 


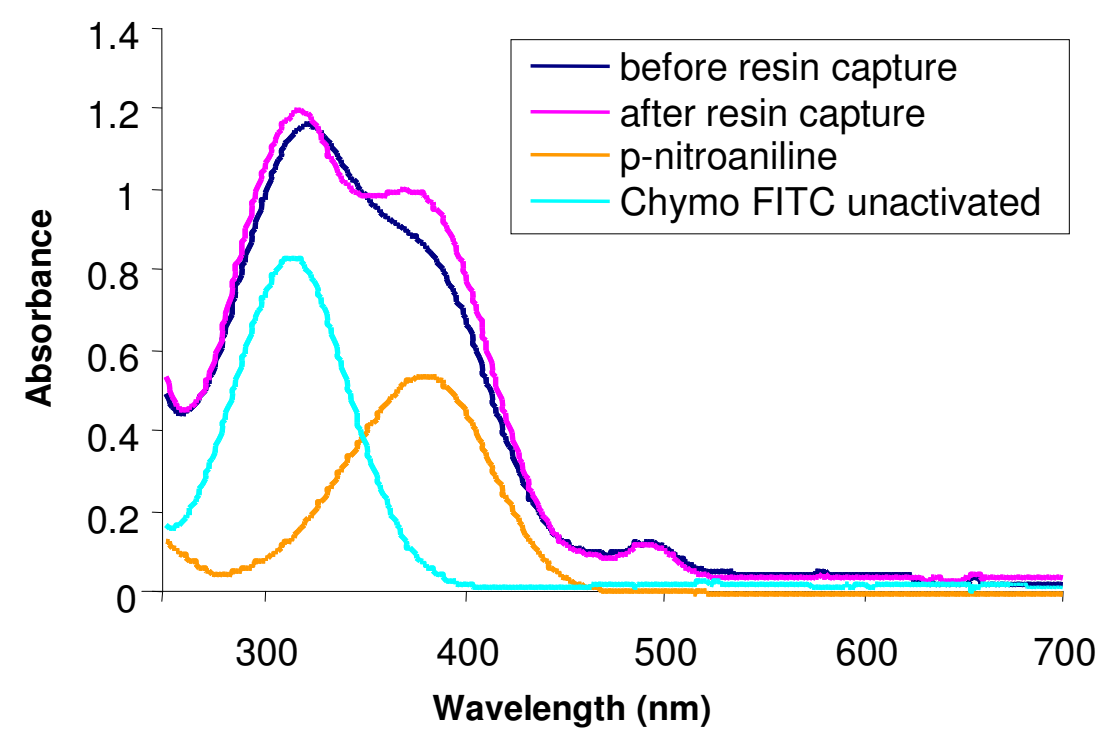

Figure S9. Normalized spectra for chymotrypsin activity assay. Absorbance at $380 \mathrm{~nm}$ indicates the hydrolysis of $p$-nitroaniline from the assay substrate. The intact assay substrate has an absorbance maximum at $305 \mathrm{~nm}$. Chymotrypsin shows similar levels of activity before (blue) and after (pink) resin capture.

Activity assay of resin captured chymotrypsinogen. After a typical resin capture procedure was performed on chymotrypsinogen modified with $\mathbf{5}$, the eluted fractions were assayed for chymotryptic activity. $20 \mathrm{uL}$ of the released protein was treated with $2.9 \mathrm{uL}$ of a $0.4 \mathrm{mg} / \mathrm{mL}$ trypsin solution in $50 \mathrm{mM}$ acetic acid. The activation of the zymogen was allowed to proceed for $10 \mathrm{~min}$ at room temperature before the addition of $80 \mathrm{uL}$ of $0.5 \mathrm{mM}$ chymotrypsin substrate I, colorometric (Suc-GGF-pNA, Calbiochem 230912) in $50 \mathrm{mM}$ Tris, $20 \mathrm{mM} \mathrm{CaCl} 2$ buffer, $\mathrm{pH}$ 7.6. The hydrolysis of p-nitroaniline from the tripeptide substrate occurred at room temperature for $30 \mathrm{~min}$. The progress of the hydrolysis reaction was followed by monitoring the absorbance at $390 \mathrm{~nm}$ (Figure S9). 


\section{Additional figures.}

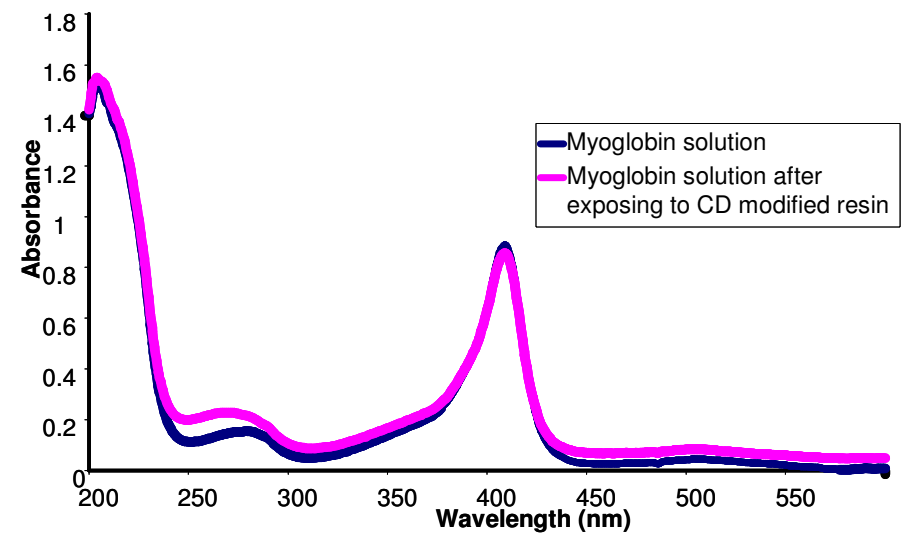

Figure S10. Complete recovery of unmodified myoglobin was obtained in the supernatant after exposure to resin 2a, confirming that the protein does not bind in the absence of the fluorescent label.

a)

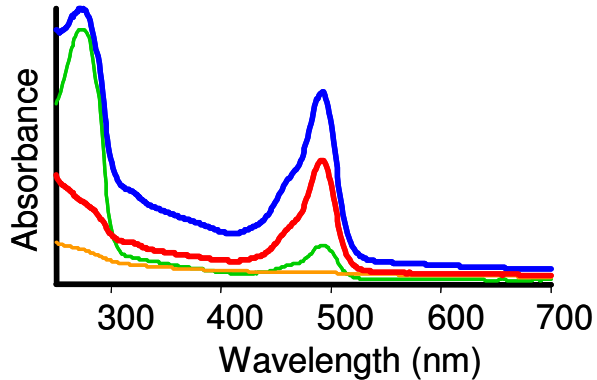

b)

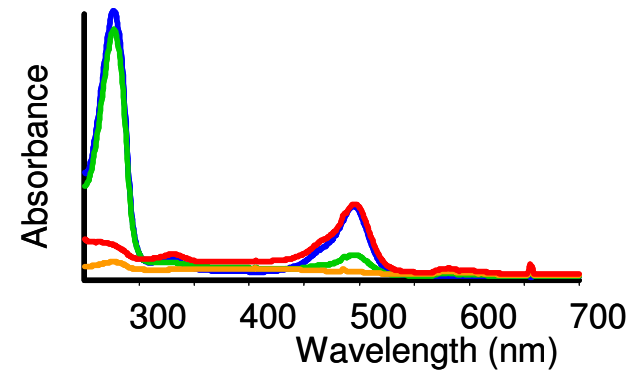

Figure S11. UV/vis spectra of modified protein resin capture: starting mixture (blue), flow through (green), water washes of resin (orange), elution with $10 \mathrm{mM}$ adamantane carboxylic acid, $100 \mathrm{mM} \mathrm{NH}_{4} \mathrm{Cl}$, pH 7 (red). (a) Chymotrypsinogen modified with FITC. (b) Subtilisn Carlsberg modified with Oregon Green-succinimidyl ester.

${ }^{1}$ Laemmli, U. K. Nature 1970, 227, 680. 